\title{
Internationalization of Higher Education in China: Chinese-Foreign Cooperation in Running Schools and the Introduction of High-Quality Foreign Educational Resources
}

\author{
Zhen Tan \\ Huazhong Normal University \\ Wuchang, Hubei 430079, China \\ Tel: 86-396-285-3006 E-mail: tanzhen9916@hotmail.com
}

\begin{abstract}
With the acceleration of the internationalization process of higher education in China, the Chinese-foreign cooperation in running schools (CFCRS) has been developing at an expeditious pace nowadays. It positively enhances the internationalization process of Chinese higher education and greatly contributes to providing the society with talents. However, the existence of lacking real practical experience in CFCRS greatly undermines introducing high-quality foreign educational resources and personnel; and this does not comply with the idea of CFCRS, which is introducing high-quality foreign educational resources and personnel. This paper deals with the research of CFCRS firstly, followed by the definition and concepts of CFCRS and educational resources. The motive of introducing high-quality foreign educational resources and personnel is annalyzed and the quality of the introduced foreign educational resources and personnel is evaluated, which will assist the improvements and benefit the internationalization of Chinese higher education.
\end{abstract}

Keywords: Internationalization of higher education, Chinese-foreign cooperation in running schools, High-quality educational resources, China

\section{Introduction}

Scott (Scott, 1998) pointed out, "investment in [higher education] can be translated into comparative economic advantage, a belief encouraged by theories of post-industrial society, which suggest that 'knowledge' has become the primary resource in advance economies". Since China's reform and opening-up, especially in the $21^{\text {st }}$ century, partnerships between Chinese and international educational bodies have been gradually increased and extended.

International cooperation in higher education is not a totally new phenomenon. Knight and de Wit (Knight \& de Wit, 1995) pointed out that there were arguments for 'the use of a common language, and of a uniform program of study and system of examination' to facilitate mobility of students and scholars and exchange of ideas in the Middle Ages and up to the end of the $17^{\text {th }}$ century. From that time, universities cooperated across national borders for the reasons of economy, politics, as well as intellect.

According to the statistics, as of 2005 there are some more than 1,000 Chinese-foreign CFCRSs and projects distributing across China's 28 provinces, autonomous regions, and municipalities (Jiang, 2006). Undoubtedly, CFCRS is for introducing high-quality educational resources to promote China's educational development. Article 3 Regulations of the People's Republic of China on Chinese-Foreign Cooperation in Running Schools (RCoCFCRS), which started taking effect on September $1^{\text {st }}, 2003$, clearly stated that the State encourages CFCRS to form partnership with high-quality foreign educational bodies to provide high-quality education (SCPRC, 2003). The idea was then again emphasized in the Opinion on Some Issues Concerning Chinese-Foreign Co-operation in Running Schools at Present (OSICCFCRSP, 2006). It is not only the fundamental principles of parties to carry out CFCRS projects but also a requisition.

However, CFCRS is still lack of real high-quality foreign educational resources.This limits the promotion of China's education development (Wen, 2005). Therefore, a study on how to ensure the intake of real high-quality educational resources becomes essential to the future of CFCRS. This paper will discuss the following questions: What is high-quality foreign educational resources? What is the reasons for introducing high-quality foreign educational resources? How to evaluate high-quality educational resources?

\section{CFCRS and High-quality Educational Resources}

Defining the main subject is a basic task of any academic study; it creates preconditions and premises for further studies. So defining CFCRS comes as the first task of all. 
What is CRCRS? Article 2 RCoCFCRS describes it as: the activities of foreign and Chinese educational organizations form partnership with the interest of recruiting Chinese domestic students( SCPRC, 2003). This concept includes the ideas that both foreign educational organisations and Chinese educational organisations are the main bodies of CRCRS, the facilities must be located within the territory of China, recruitment must be mainly Chinese national oriented, etc.

CRCRS is a new thing after China's Reform and Opening-up, and it has undergone three stages of development. ( Huang \& Wang, 2006 )

The first stage: from the beginning of the Reform and Opening-up, i. e. 1978, to 1995, before the Provisional Regulations on Chinese-Foreign Cooperation in Running Schools (PRCFCR) was enacted.

Since 1987, a lot of top Chinese universities actively conduct various forms of cooperation and exchange programs with oversea institutions from US, Japan, Germany, France, UK and Canada. Remin University of China, Fudan University have successfully held Sino-US Economy workshop and Sino-US Law workshop. Beijing Foreign Studies University and Japan Foundation collaboratively found the Beijing Japanese Studies Centre.

The second stage: from 1995 to 2003 when RCoCFCRS was enacted.

From the beginning of 1990s, as China's "Reform and Opening-up" has further progresses, Chinese higher education has speed up its internationalization process. A few domestic universities started to form partnerships with foreign educational institutions. As a result, the National Education Committee (now the Ministry of Education) enacted PRCFCR on January 6, 1995. CRCRS has been developing fast since then. According to the statistics of the Ministry of Education, by the end of 2002, there were 712 Chinese-foreign cooperatively-run schools and projects altogether in China, mostly found in East Coast area. That figure was ten times more than that of 1995( MEPRC website, 2003 ).

The third stage: after PCoCFCRS enacts in 2003.

According to PCoCFCRS, CRCRS should be developed according to the following criteria: to gradually enlarge the scale of CRCRS, to gradually improve quality, to increase the diversity of CRCRS modes. All these criteria serve for the purpose of introducing high-quality foreign educational resources.

What are high-quality resources? The definition of high-quality resources should be based on the understandings of the concepts of resources and educational resources.

Originated from economics, "resources" has been widely used in other fields. With the meaning of the basic condition for people to conduct an activity, it not only includes labor, physical and financial resources, but also includes time, place, and information, as well as referring to the related policies, culture, and conception. In addition, related crucial experience, model and research method are as well important "resources". Above all, any element that functions as the basic condition for an activity is called resources.

So, what are educational resources? Some scholars suggest, "the constitution of educational resources can be divided into principal elements and correlating elements. The educators, students, courses, and facilities are principal elements, while the brands, funds, markets, and management are correlating elements." According to the definition in the Grand Education Dictionary, educational resources are also described as "educational economic conditions", which mainly include two aspects: one refers to the laboring, physical and financial sources consumed in the process of education; the second aspect is referred as the education history and experience as well as related educational information (Gu, 1999). Whereas, according to the basic definition of "resources", the educational resources are referred to all the basic conditions needed to conduct educational activities.

Educational resources are complex collections of resources, and can be defined and analyzed from different viewpoints. In terms of the form, educational resources can be divided into tangible and intangible educational resources. In terms of the content, educational resources can be defined as educational human resources, educational material resources, educational finance resources, educational authority resources, educational space resources, educational system resources, educational academy resources, and educational reputation resources; in terms of quality educational resources can be regarded as high-quality educational resources, average educational resources, and low-quality educational resources; in terms of the application of educational resources, they are divided into valid educational resources and invalid educational resources.

What are high-quality educational resources? According to the above definitions of resources and educational resources, high-quality educational resources can be defined as followings: high-quality educational resources are the educational resources that promote education development. It is of course just a general definition and does not specify exact extent to high quality, as the quality extent conceived as high-quality varies along with different projects. As to CFCRS, not all foreign educational resources are high-quality and worthwhile being introduced. Therefore, in the practice of CFCRS, the key to success is the selection of proper cooperative subjects and the introduction of related educational resources. At the same time, the overall academic levels of the resources-exporting party, the selected subject, and related educational resources exporting policy should be taken into account. The most important is that the introduced educational resources 
should have positive effect on the enlargement of school scale, optimization of discipline structure, improvement of education quality, and effectiveness of school running. As to the evaluation of resources quality, there are three major criteria for the exporting and introducing parties of the resources: teachers' quality, teaching quality, and students' quality. There will be no good teaching effect or high-quality students without high-quality teachers. There are three criteria in evaluating the benefits of CFCRS: the benefit scale, the economic benefit, and the social benefit. The benefit scale can be measured in terms of the total number of involved teachers and students at the school; while the economic benefit can be measured in terms of the ratio of the quality, quantity of graduates and the cost of the education; the social benefit refers to the contribution and effect of CFCRS on the society, including the effects on the economic development, and the contribution to the moral and cultural constructions of the society, which reflects the real value of CFCRS as well as the purpose of introducing high-quality foreign educational resources. Hereby, the high-quality foreign educational resources in present study refer to the concepts, systems and policies, managements, courses, teaching materials, teachers, education features and styles, and other education materials, which have reached world leading level or have special feature in running schools.

\section{Motivation of Introducing High-Quality Foreign Educational Resources}

The motives for a collaborative relationship, however, are numerous.

The importance of inter-university cooperation lies not just in the free movement of staff and students, but in the creation and development of a wide range of strategic alliances that, amongst other options, facilitate the exploitation of scarce capital resources amongst partner institutions; . . provide essential ways of introducing new voices into the thinking of the university, of initiating new conversations that cross the traditional faculty or administrative boundaries, of bringing new perspectives to bear ... and confer competitive advantage on the partners (Layton , 1997).

The basic goal of CFCRS is to promote China's education development by introducing high-quality foreign educational resources. The motivation of CFCRS can be analyzed from macro, average, and micro-aspects, in which it comes from aspects of the government, educational institutions, and education consumers.

\subsection{The Macro-motivation of CFCRS}

First of all, the rise of economy, information, and market globalizations is the direct motivation of CFCRS to introduce high-quality foreign educational resources at the end of $20^{\text {th }}$ century. Surely the globalizations of economy, information, and market have increased the international competition of comprehensive national power. Actually, it is the competition of science, technology and national quality, and the most important one is the competition of education. Presently, education development is regarded as the basic national policy in many countries of the world, and the reform and development of education have been greatly accelerated. Facing the challenging situation, Chinese government realizes that the only way to rapidly improve the national education level is to increase the national education opening up, is to introduce advanced education concepts, excellent education talents, curriculum resources, and management experience. Therefore, China can change from an education importing country into an education exporting country, and finally its international competitiveness would be significantly enhanced.

Secondly, CFCRS can increase the diversity and choice scope of education to meet people's growing education demand and release the conflict between the demand and supply of education (Yuan, 2006). There is no doubt that there are still big gaps of education quantity and quality between China and those internationalized countries in top level. The contradictions of education supply and demand are mainly reflected in three aspects (Fan, 1999): firstly, in terms of quantity, the present national education supply is far from meeting the vast education demand in China, as the national education demand is growing rapidly. Whereas, the education supply increases in a much lower speed. The pressure of education demand is resulted from the growing population, individual's scope widening and level of increasing education demand. In the market economy environment, the competition of employment has become fiercer, and the education background has been taken as the key condition for employers to evaluate and select candidates. Therefore, candidate will need to have high education training to seek ideal job with good payment, which is mainly determined by education background. Secondly, in terms of education quality, the present education can not meet people's demand of high-quality education. In the current education market, high-quality education, elite education, and distinctive education are rather rare, however, people's demand for high-quality education is increasing vastly. Furthermore, the pressure of employment, the high payment temptation, and people's self-achievement urge are all in need of an increasing education supply. Thirdly, in terms of education structure, the conflict between the national education supply and demand has been reflected in a lack of high level, high-tech education, and the shortness in meeting people's increasing variety of needs.

\subsection{The Average Motivation of CFCRS}

Universities now reach out to the international community not only for academic reasons but also to enhance their influence, visibility, and/or market share (Denman, 2000).

There are three major motivations for Chinese education organizations to run Chinese-foreign cooperative schools. First of all, it is to promote the construction of their teaching and management groups, and also to promote and optimize their 
education reform by introducing high-quality foreign educational resource, learning advanced school-running and management experiences, the advanced education concepts, teaching mode, teaching content and methods, and sharing qualified teachers, etc. Secondly, it is to improve their school conditions through introducing high-quality foreign educational resources, as the tuition fee revenue for Chinese-foreign cooperatively-run schools is much higher than that of normal schools, which can be used to improve school conditions and to cover the shortage of the government's education investment. Thirdly, it is to improve the education scale, social adaptability of education and training, international applicability of the education, to increase the social benefit of school running. As in the situation of economic globalization and China's market economy, there is an demand of interdisciplinary and creative talents who are not only familiar with international economic operational regulations, but also understand the culture, as well as grasping foreign languages and advanced technical equipments. Fourthly, through introducing advanced study planning from overseas, courses setups, teaching materials and techniques, the competence and reputation of the institutions have been greatly improved, which enhance the potentials of the institutions.

\subsection{The Micro-motivation of CFCRS}

The demands of international education for consumers can be met with introduced advanced foreign curriculums, original edition of teaching stuff, and foreign teachers, which can provide the advanced foreign education without going abroad. For instance, Chinese students can learn the proper advanced foreign knowledge and English expressions in a professional core lesson, which is given by a foreign teacher. The education costs are much reduced by attending such kinds of lessons compared with going abroad. Secondly, many studying opportunities are created for students by introducing high-quality foreign educational resources. For students who want to advance their study, they can go to the foreign cooperative university to take high level courses by applying credit transfer. Thirdly, the comprehensive ability and English ability of students can be improved by introducing high-quality foreign educational resource, which enable them to become international talent with updated knowledge, broad social relationships, and also become competitive employee and candidates in both international and national employment markets.

\section{The Basic Characteristics of High-Quality Foreign Education Resources}

Introducing high-quality foreign education resources is a key to CFCRS, it is challenging at the same time. The hinge is how to distinguish high-quality education resources from those of low-quality? Comparison is the only way of distinction; a judgment can only be concluded while utilizing the educational resources. Whether the resources induction is successful should be judged by their applicability and capacity in practical teaching application. According to the basic purpose of CFCRS, introduced high-quality foreign educational resources should have three basic characteristics.

\subsection{The Relativity of Evaluations}

High-quality is relative, and also dynamic, meaning that its evaluation criteria would change along with different subjects and different places. The evaluation results of the introduced education resources are different from different introducing organizations and geographical locations. For those schools owning national top subjects, the level of the introduced resources from outside for the subjects should be higher than the national top level of these subjects. These kinds of projects are strong-strong cooperation. Whereas, for those schools owning subjects in a normal level, the introduced education resources are not necessarily better than those with national top levels, however they should be better than those normal schools. Similarly, the introduced resources for areas with different developing levels are also not necessarily the same but still should be higher than those of their introducing organization. This is called the relativity of high-quality resources. Similarly, the quality of introduced resources should be judged by their importing party, the area, and the discipline.

\subsection{The Complementarity of Application}

Drawing on the strengths of foreign organizations to offset weaknesses of the national schools is the purpose of introducing high-quality educational resources. By doing so, education reform and development can be promoted. The academic level and teaching quality can be improved. Competitive talents with international view and sense can be educated. The resources introduction can be divided into overall introduction, partial introduction, and unit introduction. The overall introduction takes place when the total available resources from the introduced school are better than those of the introducing school. Therefore the project is an overall cooperation of both parties. The partial introduction takes place when only a part of available resources from introduced school are better than those of the introducing school, in which case both parties have their own advantages and the selective introduction for both parties can be called complementary cooperation. The unit introduction takes place when only certain unit resources available from the introduced school are better than those of the introducing school and the rest of the resources of both parties are in similar levels. The unit introduction is also complementary cooperation for both parties.

\subsection{The Capacity of Resources}

The introduced education resources are supposed to live and develop in the new environment. Education resources introduction should be like organ transplanting rather than "education cloning", meaning that it should not introduce too 
much rejection reaction. The introduced resources should be useful and practical to the introducing party, meaning that they shouldn't be identical and compatible with the introducing party and have the potential for innovation. The new environment significantly influences the effects of introduced resources. The adaptability of resources is determined by their capacity to new things, which plays a great role in the digestion and absorption of the introduced resources.

\section{Conclusions}

At a presentation on institutional strategies for internationalisation, Tse (Tse, 1996) ended his speech with the following remarks: "Whatever situation you are in, go international, you won't go wrong".

It is an open world nowadays, with the economy, science and technology, culture and education being open to each other, and tends to be a plural world of interdependence. Internationalization of higher education has brought development and opportunities to China's higher education, making the introduction of high-quality foreign educational resources possible. "Appropriate introduction of high-quality foreign educational resources, such as brand, curriculum, teachers, teaching methods, management, and appraisal system and using foreign education experiences are effective ways to improving China's educational standards."(Guo, 2001)

In section 1, the concepts of CFCRS and high-quality educational resources have been defined, explaining both the concept of CFCRS and its development stages. On the basis of the analysis and understanding to the concepts of "resources" and "educational resources", high-quality foreign educational resources are suggested to be the general designation of all the concepts, systems and policies, managements, courses, teaching materials, teachers, education features and styles, and other education materials, which have reached worldwide leading situation or have special feature in running schools.

In section 2, the motivations of introducing high-quality foreign educational resources are discussed. Detailed analyses are conducted from aspects of educational institutions, the government, and education consumers. Firstly, the introduction of high-quality foreign educational resources through CFCRS is an inevitable choice of China's education opening-up and the internationalization of higher education. It is a great significance to the absorption of latest human achievements in science and technology and education, and to the expending of high-quality educational resources to meet the society's demand to high-quality education. Secondly, to educational institutions, the introduction of high quality foreign educational resources is the demand of educating international talent, innovating school-running mode, deepening education reform and promoting discipline construction, improving the quality of teachers, and widening education channels. Finally, to education consumers, their demands of education can be met without their going abroad.Thus, the costs of education are highly reduced. For those who want to advance their studies in foreign cooperative universities, the academic credits can be transferred between the cooperative universities.

In section 3, the basic characteristics of foreign high-quality educational resources are illustrated. It pointed out that, "high-quality" is a relative concept, and thus the evaluation to the high-quality foreign educational resources should be conducted relative to their subjects, the regions, and the academic disciplines. The introduction of educational resources should be with unique features, based on their capacities and in line with national and school conditions. The introduced educational resources should be an effective compensation to China's education. It promotes the reform and development of China's higher education, and enhances academic quality to cultivate talents with a global vision and international competitiveness.

In short, CFCRS are still new, and still in the exploratory stage. It is inevitable to encounter some difficulties in the implementation process. However, under the guidance of China's macroeconomic policies, CFCRS will become better to adapt to the pace of internationalization of higher education.

\section{References}

Denman, B. (2000). Globalisation and its impact on international university cooperation. Paper presented at the Organisation for Economic Cooperation and Development-Programme on Institutional Management in Higher Education Conference, Paris. September 2000.

Fan, X.Z. (1999). Education Economics. Beijing: People's Education Press. pp. 154 -161

Gu, M.Y. (1999). Grand Education Dictionary. Shanghai: Shanghai Education Press. pp. 261

Guo, F.K. (2001). WTO \& Education Reform .Guangming Daily. 27 December 2001.

Huang, T. \& Wang, G. ( 2006 ). Hope and Difficulty of the Third Running School, In Yuan, Z.G. (2006). Comments on Chinese Education Policy. Beijing: Education Science Press. pp. 29

Jiang, N.Q., \& Feng, H. (2006). New patterns of China's education opening up. China Education Daily. 25 October 2006.

Knight, J., \& de Wit, H. (1995). Strategies for internaitionalisation of higher education: Historical and conceptual perspectives. In H. de Wit(Ed), Strategies for internaitionalisation of higher education. Amsterdam: European Association for International Education Publications. pp. 5 -32 
Layton, R. A. (1997). The strategic significance of inter-university linkages. International Conference in Inter-university Cooperation and Exchange, Beijing University, 20-22 August 1997, Beijing, China.

Ministry of Education of the People's Republic of China. (2006). The Opinion on Some Issues Concerning Chinese-Foreign Cooperation in Running Schools nowadays. China Education Daily. 7 February 2006.

State Council of the People's Republic of China. (2003). Regulations of the People's Republic of China on Chinese-Foreign Cooperation in Running Schools. China Education Daily. 24 March 2003.

Scott, P. (1998). Massification, internationalization and globalization. In P. Scot(Ed), The globalization of higher education. Buckingham UK: Open University Press and Society for Research into Higher Education. pp. 108 -129

Tse, C.W.D. (1996). A president's view. Paper presented at the Institutional Strategies for Internationalization of Higher Education, $2^{\text {nd }}$ annual conference of the David C. Lam Institute for East-West Studies, Hong Kong Baptist University, Hong Kong. 25-27 November 1996.

Wen, J. (2005). Chinese-Foreign Cooperation in Running Schools expect high-quality resources. China Youth Daily. 1 Mar 2005.

Yuan, Z.G. (2006). Comment on Chinese Education Policy. Beijing: Education Science Press. pp. 35. 